\title{
HUBUNGAN DUKUNGAN KELUARGA DENGAN KEPATUHAN MINUM OBAT PADA PASIEN SKIZOFRENIA DI UNIT RAWAT JALAN RUMAH SAKIT KHUSUS JIWA SOEPRAPTO PROVINSI BENGKULU
}

\author{
Feni Eka Dianty ${ }^{1}$ Dwi Rahayu ${ }^{2}$, Neni Triana ${ }^{2}$ \\ ${ }^{1}$ Prodi D3 keperawatan FMIPA Universitas Bengkulu \\ ${ }^{2}$ Program Studi IImu Keperawatan STIKES Tri Mandiri Sakti Bengkulu \\ Email : fenieka1973@gmail.com
}

\begin{abstract}
ABSTRAK
Skizofrenia merupakan suatu penyakit jiwa yang membutuhkan dukungan keluarga dalam kepatuhan minum obat sehari-hari.Penelitian ini bertujuan untuk mengetahui Hubungan Dukungan Keluarga dengan Kepatuhan Minum Obat pada Pasien Skizofrenia di Unit Rawat Jalan Rumah Sakit Khusus Jiwa Soeprapto Provinsi Bengkulu tahun 2018.Penelitian ini menggunakan desain Cross Sectional.Populasi dalam penelitian ini adalah seluruh keluarga dan pasien Skizofrenia yang berkunjung ke UnitRawat JalanRumah Sakit Khusus Jiwa Soeprapto Provinsi Bengkulu tahun 2018.Teknik pengambilan sampel pada penelitian ini menggunakan Accidental Sampling diperoleh sampel sebesar 42 orang.Pengumpulan data dalam penelitian ini menggunakan data primer yang diperoleh langsung dari responden menggunakan kuesioner yang diisi responden, wawancara dengan responden dan data sekunder Rekam Medik untuk mendapatkan keterangan diagnosa pasien yang berobat di Unit Rawat Jalan Rumah Sakit Khusus Jiwa Soeprapto Provinsi Bengkulu tahun 2018. Hasil penelitian didapatkan: 42 orang terdapat 20 orang $(47,6 \%)$ dengan dukungan keluarga buruk, atau 22 orang $(52,4 \%)$ dengan dukungan baik; 42 orang pasien terdapat 18 orang $(42,9 \%)$ dengan kepatuhan rendah, atau 13 orang $(31,0 \%)$ dengan kepatuhan tinggi, atau 11 orang $(26,2 \%)$ dengan kepatuhan sedang; Ada hubungan yang signifikan antara Dukungan Keluarga dengan Kepatuhan Minum Obat, dengan katagori sedang dengan nilai $\mathrm{C}=0,435$ dengan approx.sig $(\mathrm{p})=0,007<0,05$. Diharapkan pada petugas kesehatan untuk memberikan penyuluhan dalam rangka untuk meningkatkan kepatuhan minum obat pada pasien Skizofrenia serta keluarga agar selalu memperhatikan kondisi pasien Skizofrenia melalui dukungan yang diberikan oleh keluarga, dengan lebih sering melakukan diskusi dengan pasien Skizofrenia tentang kepatuhan minum obat yang dialami oleh pasien Skizofrenia.
\end{abstract}

Kata Kunci :Skizofrenia, Dukungan Keluarga, Kepatuhan Minum Obat 


\section{The Relation of Family Support to Drug Adherence to Schizophrenic Patients in the Outpatient Unit of Rumah Sakit Khusus Jiwa Soeprapto Bengkulu Province}

\section{ABSTRACT}

Schizophrenia is a mental illness that requires family support in adhering to daily medication. This study aims to determine the relationship of family support with medication adherence to schizophrenic patients in the outpatient unit of the RumahSakitKhususJiwaSoepraptoin Bengkulu Province in 2018. This research uses Cross Sectional design. The population in this study were all families and schizophrenic patients who visited the Outpatient Unit of Rumah Sakit Khusus Jiwa Soeprapto Bengkulu Province in 2018. The sampling technique in this study used Accidental Sampling which obtained a sample of 42 people. Collecting data in this study using primary data obtained directly from respondents using questionnaires filled with respondents, interviews with respondents and secondary data Medical Record to obtain diagnostic information about patients who were treated at the Outpatient Unit of RumahSakitKhususJiwaSoepraptoBengkulu Province in 2018. The results obtained: 42 people there were 20 people (47.6\%) with the support of bad families, or 22 people (52.4\%) with good support; 42 patients there were 18 people (42.9\%) with low compliance, or 13 people (31.0\%) with high adherence, or 11 people (26.2\%) with moderate compliance; this iss a significant relationship between Family Support and Drug Adherence, with the medium category with a value of $C=0.435$ with approx. Sig $(p)=0.007<0.05$. It is expected that health workers to provide counseling in order to improve medication adherence to Schizophrenic patients and families to always pay attention to the condition of Schizophrenic patients through support provided by the family, by more often conducting discussions with Schizophrenic patients about medication compliance experienced by Schizophrenicpatients.

Keywords: Schizophrenia, Family Support, Drug Adherence

\section{Pendahuluan}

Gangguan jiwa adalah gangguan pada fungsi mental, yang meliputi emosi, pikiran, perilaku, motivasi daya tilik diri dan persepsi yang menyebabkan penurunan semua fungsi kejiwaan terutama minat dan motivasi sehingga mengganggu seseorang dalam proses hidup dimasyarakat. (Nasir dan Muhith 2011).

Skizofrenia merupakan gangguan jiwa yang banyak terdapat dalam masyarakat dan sering dikonotasikan dengan keadaan gila.Frekuensi di Indonesia adalah 1-3 orang setiap 1.000 orang dan pada negara maju terdapat 1 orang Skizofrenia pada setiap 100 orang.Hal ini disebabkan pada penelitian yang dilakukan di Indonesia masih kurang. Diagnosis skizofrenia lebih banyak diketemukan dikalangan golongan dengan sosio-ekonomi rendah. Beberapa pola interaksi keluarga dan faktor genetik diduga merupakan salah satu faktor penyebab terjadinya skizofrenia (Ibrahim, 2005).

$$
\text { Menurut WHO }
$$

menyatakan bahwa 24 miliar penduduk dunia menderita Skizofrenia pada usia 15 sampai dengan 35 tahun.Skizofrenia memiliki beberapa dampak bagi penderita, seperti penurunan kualitas hidup, gangguan pikiran dan persepsi, penurunan fungsi sosial dan hilangnya pekerjaan.

Berdasarkan Riset Kesehatan Dasar (Riskesdas) 2013 prevalensi Skizofrenia di Indonesia sebanyak 1.728 orang dengan prevalensi psikosis tertinggi di DI Yogyakarta dan Aceh (masing-masing 2,7\%), sedangkan yang terendah di Kalimantan Barat $(0,7 \%)$ dan di Provinsi Bengkulu prevalensi psikosis urutan keempat 
sebanyak 1,9\%. Prevalensi psikosis nasional sebesar 1,7 per mil berdasarkan tempat tinggal dan kuintil indeks kepemilikan dipaparkan pada buku Riskesdas 2013 dalam angka.

Pada survei awal yang dilakukan di Rumah Sakit Khusus Jiwa Soeprapto Provinsi Bengkulu, data yang didapatkan dari Medical Record (MR) tahun 2016 dari bulan Januari sampai Desember jumlah pasien keseluruhan tercatat 11.713 orang/ tahun rawat jalan, dengan 7.566 orang/ tahun diantaranya kasus Skizofrenia sedangkan tahun 2017 dari bulan Januari sampai Desember jumlah pasien keseluruhan tercatat 14.170 orang/ tahun rawat jalan, dengan 8.835 orang/ tahun diantaranya kasus skizofrenia. Berdasarkan data Medical Record dari tahun 2016 sampai 2017 adanya peningkatan jumlah pasien Skizofrenia sebanyak 1.269 orang/ tahun.

Keluarga merupakan satu atau lebih individu yang tergabung karena ikatan tertentu untuk saling membagi pengalaman dan melakukan pendekatan emosional serta mengidentifikasi diri mereka sebagai bagian dari keluarga (Friedman, 2010). Konflik-konflik keluarga dan interaksi keluarga yang negatif dapat menumpuk stress pada anggota keluarga yang mengalami Skizofrenia, sehingga meningkatkan resiko episode yang berulang (Mars \& Johnson, 1997 dalam Nevid, Rathus \& Greene,2003). Hampir setiap masalah kesehatan mulai dari awal sampai penyelesaiannya akan dipengaruhi oleh keluarga. Friedman (2010) mengatakan salah satu tugas keluarga dibidang kesehatan adalah memelihara kesehatan anggota keluarganya dan memberi perawatan serta dukungan kepada anggota keluarga yang sakit dan tidakdapat membantu dirinya sendiri karena cacat atau usia yang terlalu muda.

Dukungan keluarga merupakan salah satu dukungan sosial yang terdapat dimasyarakat dimana dukungan ini ialah suatu proses hubungan antara keluarga dengan lingkungan sosialnya (Friedman, 2010). Keluarga perlu memberikan dukungan yang merupakan suatu persepsi mengenai bantuan berupa perhatian, penghargaan, informasi, nasehat maupun materi yang diterima pasien Skizofrenia pasca perawatan dari anggota keluarga lainnya dalam rangka menjalankan fungsi atau tugas yang terdapat didalam sebuah keluarga.Menurut House (1985) dalam Friedman (2010), dukungan keluarga yang dapat diberikan pada pasien yaitu dukungan emosional (memberikan kenyamanan), dukungan informasional (memberikan informasi), dukungan instrumental (memfasilitasi kebutuhan) dan dukungan penilaian (sumber dan validatoridentitas).

Berdasarkan latar belakang tersebut, maka perumusan masalah dalam penelitian ini adalah "Apakah ada hubungan antara dukungan keluarga dengan kepatuhan minum obat pada pasien Skizofrenia di Unit Rawat Jalan Rumah Sakit Khusus Jiwa Soeprapto Provinsi Bengkulu Tahun 2018?'Tujuan penelitian ini untuk mempelajari hubungan dukungan keluarga dengan kepatuhan minum obat pada pasien Skizofrenia yang berkunjung ke Rumah Sakit Khusus Jiwa Soeprapto ProvinsiBengkulu.

\section{A. Metode Penelitian}

Penelitian ini dilaksanakan di Rumah Sakit Khusus Jiwa Soeprapto Provinsi Bengkulu. Jenis penelitian ini adalah survey Analitik menggunakan desain Cross Sectional. Populasi dalam penelitian ini adalah seluruh keluarga 
dan pasien Skizofrenia yang berkunjung ke Unit Rawat Jalan Rumah Sakit Khusus Jiwa Soeprapto Provinsi Bengkulu berjumlah 42 orang. Sampel penelitiaan adalah keluarga dan pasien Skizofrenia yang berkunjung ke Unit Rawat Jalan Rumah Sakit Khusus Jiwa Soeprapto Provinsi Bengkulu berjumlah 42 orang. Sampel diambil dengan menggunakan Accidental Sampling yaitu suatu teknik penetapan sampel secara kebetulan atau mengambil responden yang kebetulan bertemu peneliti saat penelitian yang dianggap cocok dengan karakteristik sampel yang dibutuhkan.Pengumpulan data dengan lembar kuesioner. Data yang digunakan adalah data primer dan sekunder.Teknik analisis data dilakukan dengan analisis Univariat dan Bivariat.Uji statistik yang digunakan adalah Chi-Square $\left(X^{2}\right)$.

\section{B. Hasil}

\section{AnalisisUnivariat}

Analisa Univariat dilakukan untuk mendapatkan gambaran hubungan dukungan keluarga dan kepatuhan minum obat yang berkunjung ke Unit Rawat Jalan Rumah Sakit Khusus Jiwa Soeprapto ProvinsiBengkulu.

Tabel 1

Gambaran Dukungan Keluarga Pada Pasien Skizofrenia

Unit Rawat Jalan RSKJ Soeprapto

Provinsi Bengkulu

\begin{tabular}{cccc}
\hline No & Dukungan Keluarga & Frekuensi (n) & Persentasi (\%) \\
\hline 1 & Buruk & 20 & 47,6 \\
2 & Baik & 22 & 52,4 \\
\hline Total & & 42 & 100,0 \\
\hline
\end{tabular}

Dari table 1 menunjukkan bahwa dari 42 orang yang berkunjung ke Unit Rawat Jalan RSKJ Soeprapto Provinsi
Bengkulu terdapat 20 orang $(47,6 \%)$ dengan dukungan buruk dan 22 orang $(52,4 \%)$ dengan dukungan baik.

Tabel 2

Gambaran Kepatuhan Minum Obat Pada Pasien Skizofrenia

Di Unit Rawat Jalan RSKJ Soeprapto

Provinsi Bengkulu

\begin{tabular}{cccc}
\hline No & Kepatuhan Minum Obat & Frekuensi (n) & Persentasi (\%) \\
\hline 1 & Rendah & 18 & 42,9 \\
2 & Sedang & 11 & 26,2 \\
3 & Tinggi & 13 & 31,0 \\
\hline Total & & 42 & 100,0 \\
\hline
\end{tabular}

Dari table 2 menunjukkan bahwa dari 42 orang yang berkunjung ke Unit Rawat Jalan RSKJ Soeprapto Provinsi Bengkulu terdapat 18 orang $(42,9 \%)$ dengan kepatuhan minum obat rendah,
13 orang $(31,0 \%)$ dengan kepatuhan minum obat tinggi dan 11 orang $(26,2 \%)$ dengan kepatuhan minum obat sedang. 


\section{AnalisisBivariat}

Analisis ini dilakukan untuk mengetahui hubungan antara variabel bebas (Dukungan Keluarga)dengan variable terikat (Kepatuhan Minum Obat) pada pasien Skizofrenia yang berkunjung ke Unit Rawat Jalan RSKJ Soeprapto Provinsi Bengkulu.

Tabel 3

Hubungan Dukungan Keluarga dengan Kepatuhan Minum Obat Pada Pasien Skizofrenia Di Unit Rawat Jalan RSKJ

Soeprapto Provinsi Bengkulu

\begin{tabular}{|c|c|c|c|c|c|c|c|c|c|c|c|}
\hline \multirow{3}{*}{$\begin{array}{c}\text { Dukungan } \\
\text { Keluarga }\end{array}$} & \multicolumn{6}{|c|}{ KepatuhanMinumObat } & \multirow{2}{*}{\multicolumn{2}{|c|}{ Total }} & \multirow{3}{*}{$X^{2}$} & \multirow{3}{*}{$p$} & \multirow{3}{*}{$C$} \\
\hline & \multicolumn{2}{|c|}{ Rendah } & \multicolumn{2}{|c|}{ Sedang } & \multicolumn{2}{|c|}{ Tinggi } & & & & & \\
\hline & $\mathrm{F}$ & $\%$ & $\mathrm{~F}$ & $\%$ & $\mathrm{~F}$ & $\%$ & $\mathrm{~F}$ & $\%$ & & & \\
\hline Buruk & 13 & 65 & 5 & 25 & 2 & 10 & 20 & 100,0 & & & \\
\hline Baik & 5 & 22,7 & 6 & 27,3 & 11 & 50 & 22 & 100,0 & 9,804 & 0,007 & 435 \\
\hline Total & 18 & 42,8 & 11 & 26,2 & 13 & 31 & 42 & 100,0 & & & \\
\hline
\end{tabular}

Berdasarkan tabel 3 dapat diketahui bahwa dari 20 orang dengan dukungan keluarga buruk terdapat 13 orang $(65 \%)$ kepatuhan minum obat rendah, 5 orang $(25 \%)$ kepatuhan minum obat sedang, dan 2 orang $(10 \%)$ kepatuhan minum obat tinggi. Sedangkan dari 22 orang dukungan keluarga baik terdapat 5 orang $(22,7 \%)$ kepatuhan minum obat rendah, 6 orang $(27,3 \%)$ kepatuhan minum obat sedang, dan 11 orang $(50 \%)$ kepatuhan minum obat tinggi.

Untuk mengetahui hubungan dukungan keluarga dengan kepatuhan minum obat pada pasien Skizofrenia yang berkunjung di Unit Rawat Jalan RSKJ Soeprapto Provinsi Bengkulu digunakan uji Chi-Square (Pearson Chi-Square).Hasil uji pearson ChiSquare didapat sebesar 9,804 dengan nilai $\operatorname{asymp} \cdot \operatorname{sig}(p)=0,007<0,05$ berarti signifikan, maka Ho ditolak dan $\mathrm{Ha}$ diterima. Jadi terdapat hubungan antara dukungan keluarga dengan kepatuhan minum obat pada pasien Skizofrenia di Unit Rawat Jalan Rumah Sakit Khusus Jiwa Soeprapto Provinsi Bengkulu.

\section{Pembahasan}

Berdasarkan hasil uji Pearson Chi-Square dan uji Contigency coefficient didapat hubungan yang signifikan antara dukungan keluarga dengan kepatuhan minum obat pada pasien Skizofrenia di Unit Rawat Jalan RSKJ Soeprapto Provinsi Bengkulu.

Hasil penelitian ini sejalan dengan Fakhruddin (2012) bahwa dukungan keluarga merupakan koping bagi keluarga itu sendiri, baik dukungan-dukungan yang bersifat eksternal maupun internal terbukti sangat bermanfaat sehingga keluarga sebagai orang yang dekat dengan pasien, harus mengetahui prinsip lima benar dalam minum obat yaitu pasien yang benar, obat yang benar, dosis yang benar, cara/rute pemberian yang benar, dan waktu pemberian obat yang benar dimana kepatuhan terjadi bila aturan pakai dalam obat yang diresepkan serta pemberiannya dirumah sakit di ikuti dengan benar. Ini sangat penting terutama pada penyakitpenyakit menahun termasuk salah satunya adalah penyakit gangguan jiwa (Skizofrenia).Faktor yang mendukung pada klien, adanya keterlibatan keluarga sebagai pengawas minum obat pada 
keluarga dengan klien dalam kepatuhan pengobatan. Menjelaskan sekitar 25\% pasien Skizofrenia, psikosis maupun gangguan mental berat gagal dalam mematuhi

program

pengobatan.Kepatuhan minum obat pada pasien Skizofrenia dapat dipengaruhi oleh efikasi minum obat, dukungan terhadap pasien, efek samping obat dan sikap pasien.

Hasil penelitian ini diperkuat dengan penelitian yang dilakukan oleh Yoga (2011), tentang hubungan dukungan keluarga dengan kepatuhan minum obat di Polikelinik Rumah Sakit Jiwa Daerah Provinsi Sumatera Utara menunjukkan bahwa ada hubungan yang signifikan antara dukungan keluarga dengan kepatuhan minum obat dengan kekambuhan pasien Skizofrenia. Semakin tinggi dukungan keluarga dan pengawasan minum obat maka kepatuhan pasien dalam minum obat juga semakintinggi.

Hasil penelitian ini diperkuat dengan penelitian yang dilakukan oleh Angel, Hendro, dan Ferdinand (2018), Hubungan dukungan keluarga dengan kepatuhan minum obat pasien Skizofrenia Di Rumah Sakit Jiwa Prof. DR. V. L.Ratumbuysang Provinsi Sulawesi Utara. Pasien gangguan jiwa dalam masa rehabilitasi yang dirawat oleh keluarga sendiri dirumah atau rawat jalan memerlukan dukungan untuk mematuhi program pengobatan.Keluarga dapat mengurangi ansietas yang disebabkan oleh penyakit tertentu dan dapat mengurangi godaan terhadap ketidakpatuhan kontinuitas pengobatan. Hasil uji statistik ChiSquare dengan tingkat kepercayaan 95 $\%(\mathrm{a}=0,05)$ diperoleh hasil $\mathrm{p}_{\text {value }}$ $0,000<0,05$. Kesimpulannya terdapat hubungan dukungan keluarga dengan kepatuhan minum obat pasien Skizofrenia di Rumah Sakit Prof. DR. V. L.
Ratumbuysang Provinsi Sulawesi Utara.

\section{Kesimpulan}

1. Dari 42 orang terdapat 22 orang $(52,4 \%)$ memberi dukungan keluargabaik.

2. Dari 42 orang terdapat 18 orang (42,9\%) kepatuhan minum obat rendah.

3. Ada hubungan yang signifikan antara dukungan keluarga dengan kepatuhan minum obat pada pasien Skizofrenia sesuai dengan katagori hubungansedang.

\section{E. DaftarPustaka}

Angel, P., Hendro, B., Ferdinand, W., (2018). Hubungan Dukungan Keluarga Dengan Kepatuhan Minum Obat Pasien Skizofrenia Di Rumah Sakit Jiwa Prof. DR. V. L. Ratumbuysang Provinsi Sulawesi Utara, Jurnal Keperawatan, Volume 6 nomor 1 : Fakultas Kedokteran Universitas Sam RatulangiManado.

Friedman. M., (2010).Keperawatan Keluarga Teori dan Praktik.Jakarta : EGC.

Ibrahim, A. S. (2005). Skizofrenia.Edisi 3. Jakarta: PT. Dian Aresta.

Nasir, A \& Muhith, A. (2011).DasarDasar Keperawatan Jiwa. Jakarta : Salemba Medika.

Nevid, J., S., Rathus, S., A., \& Greene, B., (2003). Psikologi Abnormal.Edisi 5.Jakarta : Erlangga.

Riset Kesehatan Dasar (Riskesdas). (2013). Badan Penelitian dan Pengembangan Kesehatan Kementerian RI tahun 2013.Diakses: 19 Oktober 2014, dari 
http://www.depkes.go.id/resou rces/download/general/Hasil\% 20Riskesdas\%202013.pdf.

Rumah Sakit Khusus Jiwa Soeprapto Provinsi Bengkulu (2018). Medical Record Skizofrenia 2017.

Yoga, (2011).Hubungan Dukungan Keluarga dengan Kepatuhan Pasien Minum Obat di Poliklinik Rumah Sakit Jiwa
Daerah Provinsi

SumateraUtara, Skripsi.

Sumatra utara: Fakultas

Keperawatan Unifersitas

Sumatera Utara.

World Health Organization (WHO)

(2012). Schizophrenia.

Diambil dari

http://www.who.int/mental_he alth/management/schizophreni a/en/ 